\title{
Determinants Of Fertility And Fertility Preferences In Pakistan: Comparative Secondary Analysis Of PDHS 2007-2013
}

\author{
Aisha Jalil \\ Rubeena Zakar \\ Ahmed Usman \\ \& \\ Aaisha Amjad \\ Institute of Social and Cultural Studies \\ University of the Punjab
}

\begin{abstract}
Fertility rate is on gradual decline in Pakistan like other developing countries with increased acceptance of family planning methods. Pakistan Demographic and Health Surveys revealed a slow decline from 4.1 in 2007 to 3.8 children per woman in 2013. Despite availability of nationally representative primary data, empirical researches on demographic and health determinants of fertility and fertility preferences in Pakistan are rare. The aim of this study is to assess the major differences in factors determining fertility and fertility preferences in Pakistan Demographic and Health Survey 20062007 and 2012-2013. Using two data sets Pakistan Demographic and Health Survey 2006-2007 and 2012-2013, researchers conducted a comparison of findings generated in secondary analyses. Researchers studied the association of social demographics, reproductive history and infant mortality with fertility and fertility preferences among ever-married women of reproductive age (15-49). Results are indicated using binary logistic regression and multivariate analysis. Findings support the association of social demographics of women, living sons, child mortality and reproductive history with ideal number of children; desire to reproduce more and number of living children. Injection induced labour pains, C-section deliveries, fistula problem, abortions and spotting during gestation are associated significantly with lower ideal number of children. Living sons are positively associated with ideal number of children and negatively associated with desire to reproduce more. The desire to reproduce more in association with women's age 15-29, rural place of residence and C-section deliveries has reduced over time from 2007 to 2013 in country. Complications during pregnancies and delivery are important determinants of fertility and fertility preferences among women. Further research is needed to assess the association of pregnancy and delivery problems with fertility and fertility preferences in Pakistan.
\end{abstract}

Keywords: Fertility Preferences, Fertility in Pakistan, Determinants, Reproductive History.

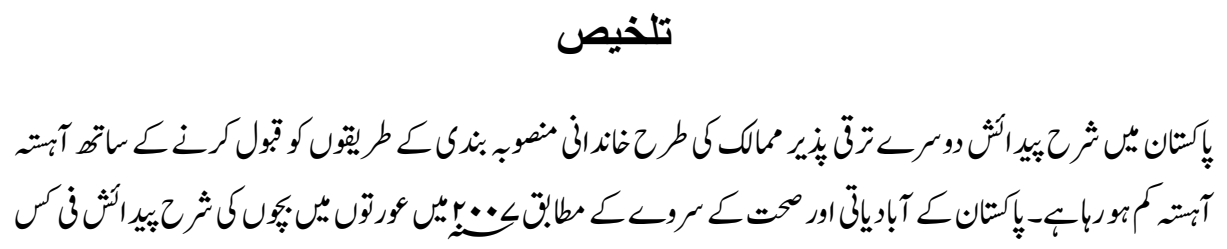




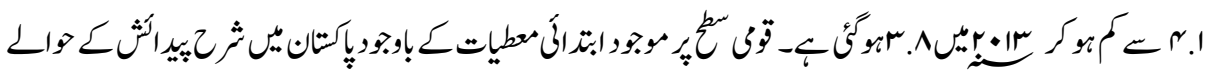

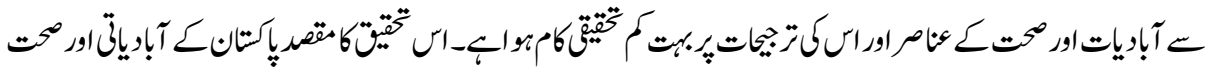

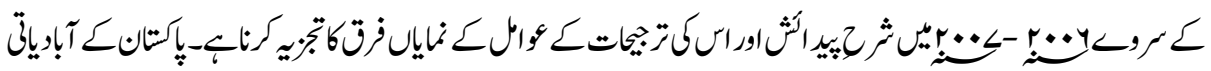

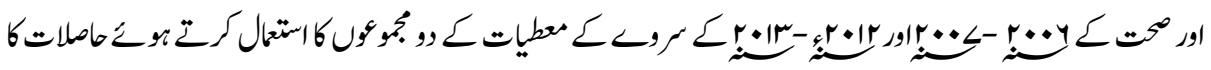

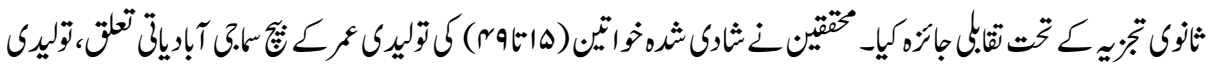

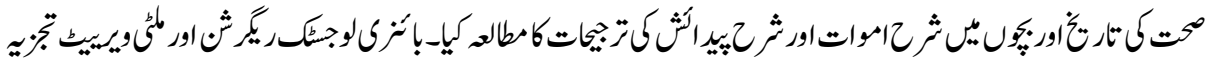

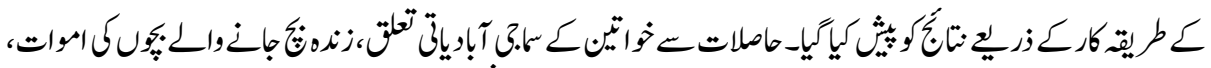

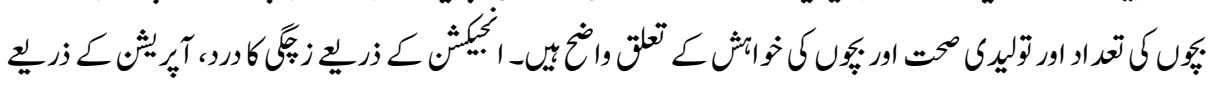

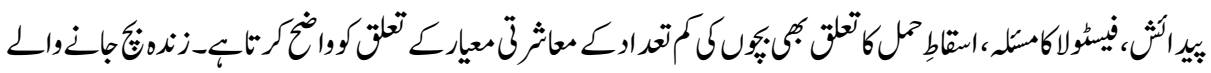

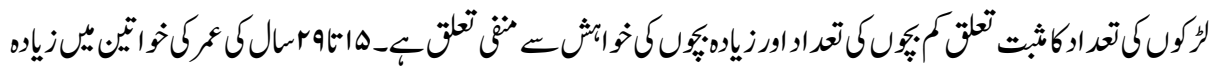

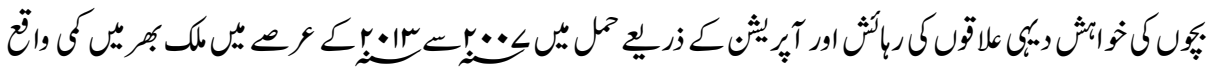

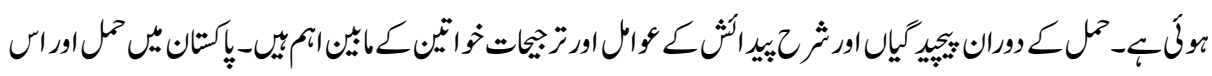

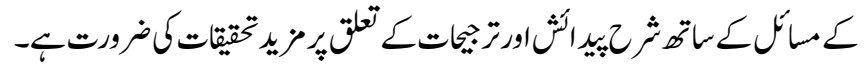

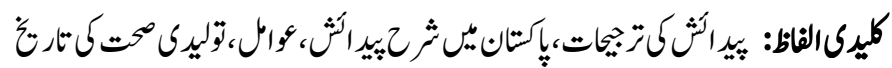

\section{Introduction}

Fertility refers to the number of live births by an average woman throughout her reproductive career. Globally, fertility rate has reduced to 3 children per women (UNDESA, 2011). However, demographic surveys in Pakistan demonstrate a steady decline infertility rate with 3.8 in 2013 and 4.1 children per women in 2007(PDHS, 20122013). This number is expected to reduce further in the coming years because average birth interval and smaller family size have increased over last 10 years in Pakistan (PDHS, 2006-07). In contrast to fertility and reproductive behaviour, the term 'fertility preference' frequently appears in empirical literature and refers to the ideal number of children a couple should have. It is assessed through ideal family size and the desire to reproduce more children (Ali, 1989). Hence, fertility preferences of a woman may not guide her actual reproductive behaviour.

Fertility surveys provide useful information on population growth prospects, demand for contraceptives and women health facilities in any country (Debpuur, Depbuur, \& Bawah, 2002). Numerous studies proved the association of demographic and health factors with fertility and fertility preferences in diverse social contexts (Adhikari, 2010; Hayford \& 
Agadjanian, 2012; Toor, 2007). However, there is dearth of empirical researches on demographic and health factors associated with fertility and fertility preferences in Pakistan (Roy et al., 2008). To our knowledge, none of researches compared the trends of demographic and health factors determining fertility and fertility preferences in Pakistan.

In low fertility societies; delayed marriage, higher education, smaller family size, wealth, absence of child death and living in rich households are found significantly associated with a low desire to reproduce more children (Mekonnen \& Worku, 2011). The women in low fertility developed countries demonstrated a higher likelihood of going through Csection deliveries on selective basis in contrast to emergency cesarean section (Ma KZM, Norton, \& Lee, 2010). The later mode of delivery is common in developing countries like Pakistan. Fifty percent of the women in Pakistan go through emergency C-section after long labour pains and other delivery related complications (Sheikh et al., 2011). The women having difficult pregnancies and $\mathrm{C}$-section deliveries are more likely to have lower ideal and actual number of children (Jayaraman, Mishra, \& Arnold, 2009). Also the number of children reproduced by women can be limited by multiple abdominal deliveries.

Reproductive history, health problems faced during pregnancy, child mortality, son preference, women's characteristics, age at first marriage, place of residence, religion, family planning methods, household headship and husband's profile significantly determine the ideal and actual family size in high fertility contexts (Bhatti \& Jeffery, 2012; McAllister et al., 2012; Pande \& Astone, 2007; Zhang, 1990). Studies in South Asian countries revealed that the son preference is one of the most important factors determining reproductive behaviour of women (Arnold, Choe, \& Roy, 1998; Brunson, 2010; Chauhduri, 2012; Larsen, Chung, \& Das Gupta, 1998; Hussain, Fikree \& Berendes, 2000).

Empirical studies in India found that the short interval of breast feeding for female children, sibling and birth order effect are significant outcomes of son targeting reproductive behaviour (Basu \& De Jong, 2010; Javachandran \& Kuziemko, 2011). The social pressure to reproduce a male child is increasing the likelihood of using sex selective abortion technologies that may generate an imbalanced sex ratio in India (Sathar \& Casterline, 1998). In contrast, sex selective abortion technologies may not be used in Pakistan due to religious prohibitions and abortion laws. According to law in Pakistan, induced abortions are legal in limited circumstances mostly when mother's life is threatened (Vlassoff et al., 2009).

Moreover, childbearing is associated with decline in women's health, age and fertility (Gilks, 1986).The reproductive health problems during gestation and at the time of delivery, also affect women's fertility preferences and subsequent reproduction (Harrison 
\& Montgomery, 2001). Reproductive history is found to be associated with death and life span of women later on (Doblhammer, 2000). Decline in child mortality is another determinant of fertility and fertility preference (Freedman, 1997). Pregnancy history and mode of delivery are not extensively studied in the context of Pakistan.

The present study addresses the gaps in the literature by assessing differentials in the association of demographic and reproductive health factors with fertility and reproductive behaviour in two recent Pakistan Demographic and Health Surveys: 2007 and 2013. The objectives of this study are to analyze: (i) The association of social demographics of women, reproductive history, child birth and mortality; and problems during gestation with ideal number of children, desire for more children and living children on the basis of primary data PDHS 2006-2007 and 2012-2013. (ii)To analyze the differentials in determinants of fertility and fertility preferences in both data sets.

\section{Materials and Methods}

We used data from Pakistan Demographic and Health Survey: 2006-2007 and 2012-2013 to carry out a secondary analysis. PDHS provides nationally representative primary data with large sample size of ever married women of reproductive age (15-49). Results of this study are indicated by binary logistic regression and multivariate logistic regression analyses. SPSS version 22.0 (SPSS, Chicago, IL, USA) is used for data storage and statistical analysis. The variables revealing a significant relationship in bivariate analysis are included in multivariate analysis. Variables that are found to be correlated and insignificant ( $\mathrm{p}$ value not less than .05) are not included in multivariate analysis. The results are based on odds ratio, $95 \%$ confidence interval and statistically significant $\mathrm{P}$ value $<0.05$.

The dependent variables are: ideal number of children, desire for more children and living children. We selected the variables that appeared the most in empirical researches for strong association with fertility and fertility preferences. However, the availability of required variables in DHS data was the major limitation of our study. Independent variables are: social demographics of women (age, education, wealth index, occupation and place of residence); reproductive history (miscarriages, stillbirths, abortions, fistula problem, deliveries by caesarian section and injection induced labour pains); child birth and mortality (children ever born, living sons, sons and daughters died); problems during gestation (Severe headache, blurring of vision, vaginal bleeding, convulsions, epigastric pains, swelling on face and hands). Dependent variables are dichotomized in order to pursue the objectives of this research. The ideal and living children are coded as 0-4 (few children) and 5+ (high children). Desire for more is categorized as 'no' and 'yes'. All these categories are recoded as 0 for 'no' and 1 for 'yes'. The independent variables 
indicate: social demographic characteristics, fertility, child mortality, health problems during pregnancies and delivery.

The variables: health problems during pregnancies and delivery are only available in the data set of 2006-07. Therefore, we conducted bivariate and multivariate analysis of PDHS 2007 to include the findings of stillbirths, injection induced labour pains, fistula and problems during gestation (Severe headache, blurring of vision, vaginal bleeding, convulsions, epigastric pains, swelling on face and hands) in this paper.

Our findings demonstrated that stillbirths, injection induced labour pains, fistula and problems during gestation (Severe headache, blurring of vision, vaginal bleeding, convulsions, epigastric pains, swelling on face and hands) are significantly associated with fertility and fertility preferences. Hence, complications during pregnancies and delivery are important determinants of fertility and fertility preferences among women. The ideal number of children ranged from 0 to 20 inclusive of numeric responses. The non-numeric responses involved: 'up to God', 'not yet decided', and 'don't know'. In the data analysis, the non-numeric responses are taken in the category of 5 to $20+$ more.

\section{Results}

\section{Social Demographic Characteristics of Women}

The group of young aged women (15-29 years)constitutes the greatest percentage with $41.4 \%$ women in data set 2006-07; whereas proportion of young women of similar age is the least of all other age groups with $20 \%$ in year 2012-13. We found significant differentials in type of place of residence in both sets of data.62\% sampled in 2006-07 and $55 \%$ in 2012-13 belonged to rural place of residence. With regard to wealth index, $20 \%$ respondents sampled in 2007-06 are categorized in rich class with lowest percentage contribution in total sample. In contrast, middle income respondents are 20\% in 2012-13.

Overall, the percentage of women completed higher education raised from $6.6 \%$ in 2007 to $7.5 \%$ in 2013 . In addition, desire to reproduce more children has drastically reduced over time from $48 \%$ in 2007 to $70 \%$ women in 2013 wanted to not to reproduce more children (see Table 1). In 2007, almost half of the women have 1 to 4 and $38.4 \%$ have more than 5 ever born children. The number of ever born children ranged from 0 to 16 in 2007 and 0 to 19 in 2013. Approximately 45\% women reported 4 to 5 ideal number children in 2007 and 2013. Similarly, women reporting to have zero number of sons who have died revealed a declining trend in child mortality with $74.1 \%$ in 2013 from previously $84 \%$ in 2007. 
24 Determinants of Fertility and Fertility Preferences in Pakistan: Comparative Secondary Analysis of PDHS 2007-2013

Table: 1

Demographic characteristics, child birth and fertility preference of women; $\mathbf{N}=\mathbf{1 0 , 0 2 3}$

\begin{tabular}{|c|c|c|}
\hline \multirow[t]{3}{*}{ Variables } & 2007 & 2013 \\
\hline & \multicolumn{2}{|c|}{ Percentages (\%) } \\
\hline & $\mathrm{N}=\mathbf{1 0 , 0 2 3}$ & $\mathrm{N}=50,238$ \\
\hline \multicolumn{3}{|l|}{ Place of Residence } \\
\hline Urban & 38 & 45 \\
\hline Rural & 62 & 55 \\
\hline \multicolumn{3}{|l|}{ Age of Respondent } \\
\hline $15-29$ & 41.4 & 19.7 \\
\hline $30-39$ & 33.6 & 40.2 \\
\hline $40-49$ & 25 & 40.1 \\
\hline \multicolumn{3}{|l|}{ Wealth Index } \\
\hline Poor & 39.8 & 41.7 \\
\hline Middle & 39.6 & 20 \\
\hline Richest & 20.5 & 38.3 \\
\hline \multicolumn{3}{|l|}{ Respondent's Occupation } \\
\hline Not working & 70.6 & 76.3 \\
\hline Agriculture employee & 10.7 & 7 \\
\hline Services & 11.8 & 6.7 \\
\hline All others $^{a}$ & 7 & 10 \\
\hline \multicolumn{3}{|l|}{ Education Level } \\
\hline Illiterate & 66.5 & 67.1 \\
\hline Primary & 13.4 & 12.4 \\
\hline Secondary & 13.4 & 12.9 \\
\hline Higher education & 6.6 & 7.5 \\
\hline \multicolumn{3}{|l|}{ Number of Living Children } \\
\hline $0-2$ & 40.5 & 14 \\
\hline $3-4$ & 26.4 & 30.5 \\
\hline $5-14$ & 33.1 & 55.7 \\
\hline \multicolumn{3}{|l|}{ Number of Children Died } \\
\hline None & 74.4 & 61.2 \\
\hline 1 & 16.6 & 22 \\
\hline $2-4$ & 8.4 & 15.6 \\
\hline 5 or more & 0.7 & 1.4 \\
\hline \multicolumn{3}{|l|}{ Desire for More Children } \\
\hline Have another & 42.2 & 20 \\
\hline Undecided & 10 & 5 \\
\hline No more & 47.6 & 70.3 \\
\hline \multicolumn{3}{|l|}{ Number of Living Sons } \\
\hline 0 & 24.6 & 7 \\
\hline $1-2$ & 45.8 & 46.6 \\
\hline $3-10$ & 29.6 & 46.6 \\
\hline \multicolumn{3}{|l|}{ Number of Sons Died } \\
\hline 0 & 83.6 & 74.1 \\
\hline $1-6$ & 16.4 & 25.9 \\
\hline \multicolumn{3}{|l|}{ Ideal Number of Children } \\
\hline$\leq 3$ & 27.3 & 20.2 \\
\hline $4-5$ & 44.9 & 45.4 \\
\hline $6+$ & 27.8 & 34.4 \\
\hline
\end{tabular}

a professional, technical, managerial, clerical, sales, household and domestic worker, skilled and unskilled manual worker. *6+ includes non numeric responses.

\section{Determinants of Fertility and Fertility Preferences}

The binary logistic regression analysis of PDHS (2006-07) indicated that most of the social-demographic variables are significantly associated with number of living children and reproductive preferences. According to bivariate analysis of 2007 data, desire to reproduce more children is higher among the young women $(\mathrm{OR}=30.33,95 \% \mathrm{CI}=26.05$ $35.3)$ as compare to the women of older age groups. On the contrary, women aged 15-29 
are less likely to have desire to reproduce more $(\mathrm{OR}=.04,95 \% \mathrm{CI}=.035-.042)$ in year 2012-13.In 2007, women living in rural places are more likely to have desire to reproduce more in contrast to women living in urban areas. In contrast, women living in rural areas are found to have higher odds of no desire to reproduce more (see table 2).

Table: 2

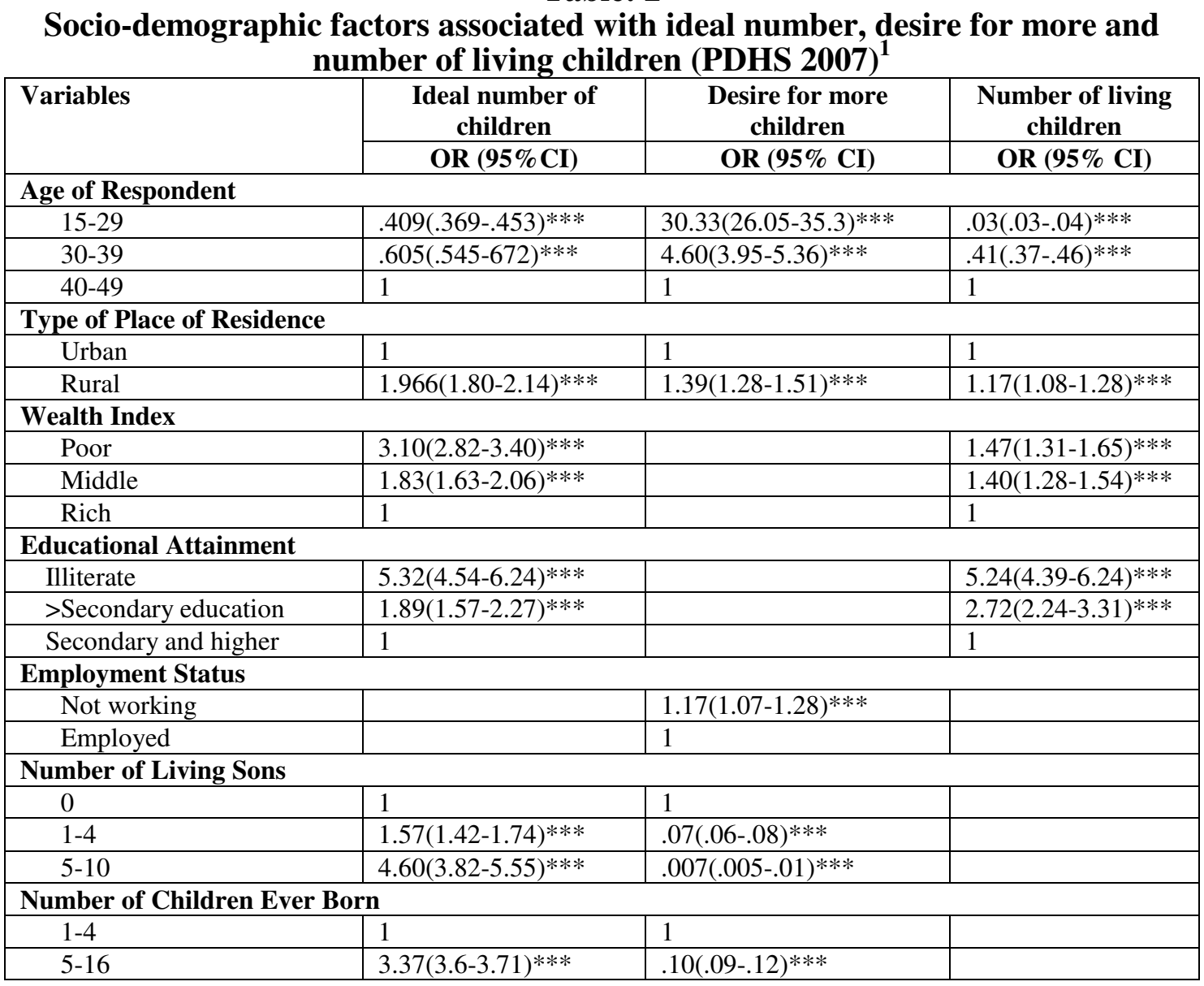

1 the table shows results of binary logistic regression analysis. insignificant results are not stated in the table abbreviations: $\mathrm{OR}=$ odds ratio, $\mathrm{CI}=$ confidence interval, $1=$ reference category

$\mathrm{p}$ value $* * *$ highly significant,

In addition, analysis of both data sets for the association of number of living sons and ideal number of children revealed similar trend. The women with many sons have higher likelihood of possessing high ideal number of children, that is: $\mathrm{OR}=4.6,95 \% \mathrm{CI}=(3.82$ 5.55) in 2007 and $\mathrm{OR}=3.38,95 \% \mathrm{CI}=(3.53-4.14)$ in 2013. However, women having many living sons are more likely to have desire to reproduce more (see table 3). In contrast, many sons are associated with lower desire to reproduce more in 2007. In both data sets, women who reproduced many children are found to have higher number of idealized children. 
26 Determinants of Fertility and Fertility Preferences in Pakistan: Comparative Secondary Analysis of PDHS 2007-2013

Table: 3

Socio-demographic factors associated with ideal number, desire for more and number of living children (PDHS 2013) ${ }^{1}$

\begin{tabular}{|c|c|c|c|}
\hline \multirow[t]{2}{*}{ Variables } & Ideal number of children & Desire for more children & $\begin{array}{c}\text { Number of living } \\
\text { children }\end{array}$ \\
\hline & OR $(95 \% \mathrm{CI})$ & OR $(95 \%$ CI $)$ & OR $(95 \% \mathrm{CI})$ \\
\hline \multicolumn{4}{|l|}{ Age of Respondent } \\
\hline $15-29$ & $.38(.36-.40)^{* * * *}$ & $.04(.035-.042)^{* * * * *}$ & $.05(.046-.052)^{* * * *}$ \\
\hline $30-39$ & $.65(.62-.67)^{* * * *}$ & $.18(.17-.20)^{* * * *}$ & $.39(.37-.41)^{* * * *}$ \\
\hline $40-49$ & 1 & 1 & 1 \\
\hline \multicolumn{4}{|l|}{ Type of Residence } \\
\hline Urban & 1 & 1 & 1 \\
\hline Rural & $1.72(1.66-1.78)^{\text {**** }}$ & $.94(.88-.99)^{*}$ & $1.29(1.25-1.34)^{* * * *}$ \\
\hline \multicolumn{4}{|l|}{ Wealth Index } \\
\hline Poor & $3.90(3.74-4.06)^{* * * *}$ & & $1.97(1.89-2.05)^{* * * *}$ \\
\hline Middle & $2.02(1.92-2.13)^{* * * *}$ & & $1.79(1.71-1.88)^{\text {***** }}$ \\
\hline Rich & 1 & & 1 \\
\hline \multicolumn{4}{|l|}{ Educational Attainment } \\
\hline Illiterate & $9.49(8.6-10.47)^{* * * *}$ & $1.61(1.46-1.77)^{* * * *}$ & $9.97(9.11-10.91)^{* * * *}$ \\
\hline$>$ Secondary & $2.91(2.61-3.25)^{* * * *}$ & $1.85(1.65-2.06)^{* * * *}$ & $4.80(4.34-5.30)^{3 . * *}$ \\
\hline Secondary and higher & 1 & 1 & 1 \\
\hline \multicolumn{4}{|l|}{ Employment Status } \\
\hline Not working & & & $.89(.86-.93)^{* * * *}$ \\
\hline Employed & & & 1 \\
\hline \multicolumn{4}{|l|}{ Number of Living Sons } \\
\hline 0 & 1 & 1 & 1 \\
\hline $1-4$ & $1.32(1.22-1.43)^{* * * *}$ & $6.97(6.42-7.57)^{* * * *}$ & $7.03(6.15-8.05)^{* * * *}$ \\
\hline $5-10$ & $3.82(3.53-4.14)^{* * * *}$ & $31.44(28.69-34.45)^{* * * *}$ & $69.7(60.8-79.93)^{* * *}$ \\
\hline \multicolumn{4}{|c|}{ Number of Children Ever Born } \\
\hline $1-4$ & 1 & & \\
\hline $5-16$ & $3.38(2.97-3.86)^{* * * * *}$ & & \\
\hline \multicolumn{4}{|l|}{ Children Died } \\
\hline No & 1 & 1 & \\
\hline Yes & $1.91(1.85-1.98)^{* * * *}$ & $1.62(1.55-1.70)^{* * * *}$ & \\
\hline \multicolumn{4}{|l|}{ Daughters Died } \\
\hline No & 1 & 1 & 1 \\
\hline Yes (1 to 5) & $1.68(1.61-1.75)^{* * * *}$ & $1.39(1.32-1.47)^{* * *}$ & $1.74(1.66-1.81)^{\text {***** }}$ \\
\hline \multicolumn{4}{|l|}{ Sons Died } \\
\hline No & 1 & 1 & 1 \\
\hline Yes & $1.84(1.76-1.92)^{* * * *}$ & $1.54(1.45-1.63)^{* * *}$ & $1.73(1.58-1.807)^{* * * *}$ \\
\hline \multicolumn{4}{|l|}{ History of Abortions } \\
\hline No & 1 & 1 & 1 \\
\hline Yes & $1.25(1.21-1.30)^{* * * *}$ & $1.39(1.33-1.45) * * *$ & $1.30(1.25-1.35)^{* * * * 6}$ \\
\hline \multicolumn{4}{|l|}{ Miscarriages } \\
\hline No & & 1 & 1 \\
\hline Yes & & $1.39(1.33-1.45)^{* * * *}$ & $1.56(1.55-1.85)^{* * * *}$ \\
\hline \multicolumn{4}{|l|}{ C Section Delivery } \\
\hline No & 1 & 1 & 1 \\
\hline Yes & $.27(.23-.32)^{* * * * *}$ & $.72(.64-80)^{* * *}$ & $.24(.20-.29)^{* * * *}$ \\
\hline
\end{tabular}

1 the table shows results of binary logistic regression analysis. insignificant results are not stated in the table abbreviations: $\mathrm{OR}=$ odds ratio, $\mathrm{CI}=$ confidence interval, $1=$ reference category

$\mathrm{p}$ value $* * *=<.001, * *<.01, *<.05$ 


\section{Child Mortality and Reproductive History}

Child mortality is found to be associated with higher number of ideal and living children (See table 3 and 4). The women with male child mortality are more likely to have high number of ideal $(\mathrm{OR}=1.57,95 \% \mathrm{CI}=1.42-1.74)$ and living children $(\mathrm{OR}=1.93,95 \% \mathrm{CI}=$ 1.74-2.14) in 2007. The history of abortions and miscarriages are associated with desire for more children in both cases. Terms 'miscarriage' and 'abortion' are clearly distinguished and exclusively used as separate variables in 2006-07 data. Miscarriage is referred to the case of termination of pregnancy that is unplanned and not desired. On the contrary, abortion is planned termination in critical circumstances. Women with history of stillbirths are more likely to desire more children and are less likely to have higher number of living children. Data on stillbirths is not available in 2012-2013.

Table: 4

Indicators of child mortality in association with fertility preference and fertility ${ }^{1}$ (PDHS 2006-07) ${ }^{2}$

\begin{tabular}{|c|c|c|c|}
\hline \multirow[t]{2}{*}{ Variables } & $\begin{array}{c}\text { Ideal number of } \\
\text { children }\end{array}$ & $\begin{array}{c}\text { Desire for more } \\
\text { children }\end{array}$ & $\begin{array}{c}\text { Number of living } \\
\text { children }\end{array}$ \\
\hline & OR $(95 \% \mathrm{CI})$ & OR (95\% CI) & OR $(95 \%$ CI $)$ \\
\hline \multicolumn{4}{|c|}{ Number of Children Died } \\
\hline No & 1 & 1 & 1 \\
\hline Yes & $1.57(1.42-1.74) * * *$ & $.62(.55-.68) * * *$ & $1.93(1.74-2.14)^{* * *}$ \\
\hline \multicolumn{4}{|c|}{ Number of Sons Died } \\
\hline No & 1 & 1 & 1 \\
\hline Yes (1 to 6$)$ & $1.59(1.41-1.79)^{* * *}$ & $.65(.57-.73) * * *$ & $1.78(1.58-2.007) * * *$ \\
\hline \multicolumn{4}{|c|}{ Number of Daughters Died } \\
\hline No & 1 & 1 & 1 \\
\hline Yes (1 to 5) & $1.57(1.39-1.77)^{* * *}$ & $.56(.49-.64) * * *$ & $1.85(1.64-2.09)^{* * *}$ \\
\hline \multicolumn{4}{|c|}{ History of Abortions } \\
\hline No & 1 & 1 & 1 \\
\hline Yes & $.701(.61-.81)^{* * *}$ & $1.88(1.64-2.16)^{* * *}$ & $.62(.54-.73) * * *$ \\
\hline \multicolumn{4}{|l|}{ Miscarriages } \\
\hline No & 1 & 1 & 1 \\
\hline Yes $(1-5)$ & $.71(.59-.85) * * *$ & $2.06(1.75-2.44) * * *$ & $.64(.53-.77) * * *$ \\
\hline \multicolumn{4}{|l|}{ Stillbirths } \\
\hline No & & 1 & 1 \\
\hline Yes (1-3) & & $1.86(1.41-2.46)^{* * *}$ & $.61(.44-.83)^{* * *}$ \\
\hline
\end{tabular}

1 Table is based on the results of bivariate analysis. the insignificant results are not given in the table

2 data on stillbirths, fistula problem, problems during pregnancy, injection induced labor pains are omitted from PDHS 2013 data set..

Abbreviations: CI, Confidence Interval; OR, Odds Ratio; 1, Reference Category;

$\mathrm{P}$ value $<.001=* * *,<.01=* *,<.05=*$ 
The women suffering from severe headache, blurred vision and fits or convulsions are more likely to have no desire for more children. Vaginal bleeding/ spotting are found to be associated with few ideal children (see Table 5 for odd ratios and $\mathrm{p}$ values). The variables of problems faced during pregnancy except deliveries by $\mathrm{C}$-section, are not available in 2012-13 data set. Moreover, women who went through one or few C-sections are less likely to have higher ideal and actual number of children. However, delivery by $\mathrm{C}$ section and desire for more children are associated with odds of 2.33 in year 2007. We found inverse from the analysis of variables in PDHS 2013 as women with C-section deliveries are less likely have desire to reproduce more children perhaps due to raising awareness among women regarding reproductive health and medical procedures.

Table: 5

Reproductive history in association with fertility preferences and fertility (PDHS 2006-07) ${ }^{1}$

\begin{tabular}{|c|c|c|c|}
\hline \multirow[t]{2}{*}{ Variables } & $\begin{array}{l}\text { Ideal number of } \\
\text { children }\end{array}$ & $\begin{array}{l}\text { Desire for more } \\
\text { children }\end{array}$ & $\begin{array}{l}\text { Number of living } \\
\text { children }\end{array}$ \\
\hline & OR (95\% CI) & OR (95\% CI) & OR (95\% CI) \\
\hline \multicolumn{4}{|c|}{ Severe Headache } \\
\hline No & 1 & 1 & 1 \\
\hline Yes & $1.41(1.25-1.59) * * *$ & $.85(.76-.96)^{* *}$ & $1.46(1.29-1.65) * * *$ \\
\hline \multicolumn{4}{|l|}{ Blurred Vision } \\
\hline No & 1 & 1 & 1 \\
\hline Yes & $1.29(1.13-1.46) * * *$ & $.71(.62-.798) * * *$ & $1.796(1.58-2.04) * * *$ \\
\hline \multicolumn{4}{|c|}{ Swelling of Hands } \\
\hline No & & & 1 \\
\hline Yes & & & $1.18(1.03-1.35)^{*}$ \\
\hline \multicolumn{4}{|l|}{ Swelling of Face } \\
\hline No & & & 1 \\
\hline Yes & & & $1.20(1.05-1.38)^{*}$ \\
\hline \multicolumn{4}{|c|}{ Vaginal Bleeding/ Spotting } \\
\hline No & 1 & & \\
\hline Yes & $.64(.499-.81) * * *$ & & \\
\hline \multicolumn{4}{|c|}{ Fits/ Convulsions } \\
\hline No & & 1 & 1 \\
\hline Yes & & $.71(.52-.96)^{*}$ & $1.54(1.13-2.11) * *$ \\
\hline \multicolumn{4}{|c|}{ Epigastria Pains } \\
\hline No & 1 & & 1 \\
\hline Yes & $1.38(1.22-1.56) * * *$ & & $1.41(1.24-1.60) * * *$ \\
\hline \multicolumn{4}{|c|}{ Deliveries by Injection Induced Labour Pains } \\
\hline No & 1 & 1 & 1 \\
\hline Yes (1-6) & $.57(.52-.63) * * *$ & $2.53(2.29-2.78) * * *$ & $.52(.47-.57) * * *$ \\
\hline \multicolumn{4}{|c|}{ Deliveries by c Section } \\
\hline No & 1 & 1 & 1 \\
\hline Yes (1-4) & $.32(.25-.41)^{* * *}$ & $2.33(1.92-2.84) * * *$ & $.16(.12-.22) * * *$ \\
\hline \multicolumn{4}{|c|}{ Urine/ Stool Fistula Problem } \\
\hline No & 1 & & \\
\hline Yes & $.51(.26-.995) *$ & & \\
\hline
\end{tabular}

1 Table is based on the results of bivariate analysis

Abbreviations: CI, Confidence Interval; OR, Odds Ratio; 1, Reference Category

$\mathrm{P}$ value $<.001=* * *,<.01=* *,<.05=*$ 


\section{Findings of Multivariate Analysis}

The results of multivariate analysis are demonstrated in Table 6, 7 and 8. Using PDHS 2006-07, we found that women's demographic and health factors are significantly associated with fertility and fertility preferences. The results showed that the young women (15-29) are 19 times more likely to have desire to reproduce more children as compare to the aged women. On the contrary, multivariate analysis of significant variables in data set of DHS 2012-13demonstrated that young women (15-29) are only .09 times likely to desire for more children (see table 8). In 2007, women living in rural residences are found to be more likely have five plus ideal number of children in contrast to their urban counterpart (in table 6). The women in rural places of residence demonstrated odds of .83 to have high ideal number of children in year 2013.

Table: 6

Multivariate analysis results: socio-demographic predictors of fertility and fertility preferences among $\mathrm{N}=\mathbf{1 0 , 0 2 3}$ ever married women of reproductive age (15-49) sampled in PDHS 2007

\begin{tabular}{|c|c|c|c|}
\hline Variables & $\begin{array}{c}\text { Ideal number of } \\
\text { children }\end{array}$ & $\begin{array}{c}\text { Desire for more } \\
\text { children }\end{array}$ & $\begin{array}{c}\text { Number of living } \\
\text { children }\end{array}$ \\
\hline \multicolumn{4}{|l|}{ Age of Respondent } \\
\hline $15-29$ & $.44(.39-.51) * * *$ & 19.03(15.76-22.9)*** & $.04(.03-.044) * * *$ \\
\hline $30-39$ & $.64(.56-.72) * * *$ & $4.45(3.69-5.37)^{* * *}$ & $.41(.36-.47) * * *$ \\
\hline $40-49$ & 1 & 1 & 1 \\
\hline \multicolumn{4}{|l|}{ Type of Residence } \\
\hline Urban & 1 & 1 & \\
\hline Rural & $1.21(1.07-1.37)^{* *}$ & $1.24(1.08-1.43)^{* *}$ & \\
\hline \multicolumn{4}{|l|}{ Wealth Index } \\
\hline Poorest/poor & $2.02(1.75-2.33) * * *$ & & $1.38(1.17-1.62)^{* *}$ \\
\hline Middle & $1.26(1.08-1.46)^{* *}$ & & $1.28(1.09-1.52)^{* *}$ \\
\hline Rich/ richest & 1 & & 1 \\
\hline \multicolumn{4}{|l|}{ Educational Attainment } \\
\hline Illiterate & $2.93(2.41-3.57) * * *$ & & $4.68(3.77-5.81) * * *$ \\
\hline$<$ Secondary education & $1.56(1.27-1.93) * * *$ & & $3.39(2.70-4.25) * * *$ \\
\hline$\geq$ Secondary education & 1 & & 1 \\
\hline \multicolumn{4}{|l|}{ Employment Status } \\
\hline Not working & $1.19(1.06-1.33)^{* *}$ & $1.21(1.06-1.38)^{* *}$ & \\
\hline Working & 1 & 1 & \\
\hline \multicolumn{4}{|l|}{ Number of Living Sons } \\
\hline 0 & 1 & 1 & \\
\hline $1-4$ & $1.27(1.09-1.49)^{* *}$ & $.12(.096-.14) * * *$ & \\
\hline $5-10$ & $2.30(1.80-2.94)^{* * *}$ & $.023(.014-.04) * * *$ & \\
\hline \multicolumn{4}{|l|}{ Children Ever Born } \\
\hline $1-4$ & 1 & 1 & \\
\hline $5-16$ & $3.37(3.6-3.7)^{* * *}$ & $.10(.09-.12)^{* * *}$ & \\
\hline
\end{tabular}

1 The table contains results of variables that are found significant in multivariate analysis. Multicollinearity is checked between variables before entering into multivariate analysis. Empty spaces indicate insignificant results.

Abbreviations: CI, Confidence Interval; OR, Odds Ratio; 1, Reference Category;

$\mathrm{P}$ value $<.001=* * *,<.01=* *,<.05=*$ 
Moreover, illiterate, poor women who are not doing any paid job are more likely to have higher ideal and actual number of children in both data sets being compared. Women with history of abortions are less likely to have five plus ideal and actual number of children in 2007. Women with child mortality are more likely to have higher ideal and actual number of children. Deliveries by C-section are associated with lower likelihood of five plus ideal and actual number of children in both data sets. Vis-à-vis a higher likelihood of desire to reproduce moreis assessed in 2007 and low likelihood of reproducing more in 2013(see table 7 and 8).

Table: 7

Multivariate analysis results: Reproductive history indicators of fertility and fertility preferences among $N=\mathbf{1 0 , 0 2 3}$ ever married women of reproductive age (1549) sampled in PDHS 2007

\begin{tabular}{|c|c|c|c|}
\hline Variables & $\begin{array}{c}\text { Ideal number of } \\
\text { children }\end{array}$ & $\begin{array}{c}\text { Desire for more } \\
\text { children }\end{array}$ & $\begin{array}{c}\text { Number of living } \\
\text { children }\end{array}$ \\
\hline \multicolumn{4}{|l|}{ Sons Died } \\
\hline No & & 1 & 1 \\
\hline Yes (range: 1 to 6 ) & & $1.49(1.27-1.74) * * *$ & $1.62(1.43-1.83) * * *$ \\
\hline \multicolumn{4}{|l|}{ Daughters Died } \\
\hline No & & 1 & 1 \\
\hline Yes (range: 1 to 5 ) & & $1.24(1.05-1.46)^{* *}$ & $1.68(1.48-1.90) * * *$ \\
\hline \multicolumn{4}{|l|}{ History of Abortions } \\
\hline No & 1 & & 1 \\
\hline Yes & $.499(.33-.75) * *$ & & $.598(.41-.88)^{* *}$ \\
\hline \multicolumn{4}{|l|}{ Miscarriages } \\
\hline No & & 1 & \\
\hline Yes (range: $1-5)$ & & $1.90(1.26-2.88)^{* *}$ & \\
\hline \multicolumn{4}{|l|}{ Stillbirths } \\
\hline No & & 1 & \\
\hline Yes (range: $1-3$ ) & & $1.63(1 . .2-2.59)^{*}$ & \\
\hline \multicolumn{4}{|c|}{ Deliveries with Injection Induced Labour Pains } \\
\hline No & 1 & & 1 \\
\hline Yes (range: $1-6)$ & $.35(.27-.45)^{* * *}$ & & $.76(.67-.87)^{* * * *}$ \\
\hline \multicolumn{4}{|l|}{ Delivery by C-Section } \\
\hline No & 1 & 1 & 1 \\
\hline Yes (range: $1-4)$ & $.59(.54-.66)^{* * *}$ & $1.295(1.06-1.59)^{*}$ & $.22(.16-.31)^{* * * *}$ \\
\hline \multicolumn{4}{|c|}{ Experienced Fistula Problem } \\
\hline No & 1 & & \\
\hline Yes & $.49(.25-.97)^{*}$ & & \\
\hline \multicolumn{4}{|l|}{ Severe Headache } \\
\hline No & 1 & & 1 \\
\hline Yes & $1.31(1.15-1.4)^{* * *}$ & & $1.22(1.06-1.40) * *$ \\
\hline \multicolumn{4}{|l|}{ Blurring Vision } \\
\hline No & & 1 & 1 \\
\hline Yes & & $.73(.64-.83)^{* * * *}$ & $1.56(1.35-1.80) * * *$ \\
\hline \multicolumn{4}{|c|}{ Vaginal Bleeding/ Spotting } \\
\hline No & 1 & & \\
\hline Yes & $.577(.45-.74) * * *$ & & \\
\hline \multicolumn{4}{|l|}{ Epigastric Pains } \\
\hline No & 1 & & 1 \\
\hline Yes & $1.28(1.12-1.46)^{* * *}$ & & $1.17(1.02-1.35)^{*}$ \\
\hline
\end{tabular}

Abbreviations: $\mathrm{CI}=$ Confidence Interval; OR=Odds Ratio; $1=$ Reference Category

$\mathrm{P}$ value $<.001=* * *,<.01=* *,<.05=*$ 
The women with blurring vision in pregnancy are more likely to have no desire to reproduce more $(\mathrm{OR}=.73,95 \% \mathrm{CI}=.64-.83)$ but have higher number of living children $(\mathrm{OR}=1.56,95 \% \mathrm{CI}=1.35-1.80)$. The higher ideal and living children among the women suffering from severe headache, blurring of vision and epigastric pains are perhaps due to the fact that women in Pakistani society consider the health problems as common problem of pregnancy. Severe reproductive health problems: vaginal bleeding, injection induced labor pains, fistula problem and C-section are associated with few ideal and living children. The women with history of miscarriages, C-section deliveries and stillbirths have high desire to reproduce more. The women gone through caesarian sections and used injection induced labor pains for deliveries also have high likelihood of low ideal and actual number of children. Women who have reported vaginal bleeding in pregnancy are more likely to have low ideal number of children $(\mathrm{OR}=.577,95 \% \mathrm{CI}=.45$ .74) (See table 7).

Table: 8

Determinants of ideal number, desire for more and number of living children; Multivariate logistic regression analysis of PDHS 2013 data $^{1}$

\begin{tabular}{|c|c|c|c|}
\hline \multirow[t]{2}{*}{ Variables } & $\begin{array}{c}\text { Ideal number } \\
\text { of children } \\
(\text { Few/5+) }\end{array}$ & $\begin{array}{l}\text { Desire for more } \\
\text { children } \\
(\mathrm{N} / \mathrm{Y})\end{array}$ & $\begin{array}{c}\text { Number of living } \\
\text { children } \\
\text { (Few/5+) }\end{array}$ \\
\hline & AOR (95\% CI) & $\operatorname{AOR}(95 \% \mathrm{CI})$ & $\operatorname{AOR}(95 \% \mathrm{CI})$ \\
\hline \multicolumn{4}{|l|}{ Age of Respondent } \\
\hline $15-29$ & $.39(.38-.42)^{*}$ & $.09(.08-.09)^{*}$ & $.05(.046-.05)^{* * * *}$ \\
\hline $30-39$ & $.66(.64-.69)^{* * *}$ & $.20(.22-.26)^{* * * *}$ & $.41(.40-.43)^{* * * *}$ \\
\hline $40-49$ & 1 & 1 & 1 \\
\hline \multicolumn{4}{|l|}{ Type of Residence } \\
\hline Urban & 1 & & 1 \\
\hline Rural & $.83(.79-.87)^{* * * *}$ & & $.82(.78-.86)^{* * * *}$ \\
\hline \multicolumn{4}{|l|}{ Wealth Index } \\
\hline Poor & $\underset{* * *}{2.68(2.54-2.83)}$ & & $1.60(1.50-1.70)^{* * *}$ \\
\hline Middle & $1.49(1.41-1.58)$ & & $1.52(1.43-1.62)^{* * * *}$ \\
\hline Rich & 1 & & 1 \\
\hline \multicolumn{4}{|c|}{ Educational Attainment } \\
\hline Illiterate & $5.70(5.12-6.30)$ & $.87(.79-.97)^{* * *}$ & $9.45(8.55-10.44)^{* * * * *}$ \\
\hline$>$ Secondary & $\underset{* * *}{2.43(2.17-2.72)}$ & $1.19(1.07-1.35)^{*}$ & $5.72(5.15-6.38)^{* * * *}$ \\
\hline Secondary / higher & 1 & 1 & 1 \\
\hline
\end{tabular}


32 Determinants of Fertility and Fertility Preferences in Pakistan: Comparative Secondary Analysis of PDHS 2007-2013

\begin{tabular}{|c|c|c|c|}
\hline \multicolumn{4}{|c|}{ Number of Living Sons } \\
\hline 0 & 1 & 1 & 1 \\
\hline $1-4$ & $.88(.81-.96)^{* *}$ & $\begin{array}{l}6.97(6.42- \\
7.57)^{* * * *}\end{array}$ & $2.78(2.23-)^{* * * *}$ \\
\hline $5-10$ & ${ }_{* * * *}^{1.83}(1.49-1.78)$ & $\begin{array}{l}31.44(28.69- \\
34.45)^{* * *}\end{array}$ & 19.08()$^{* * *}$ \\
\hline \multicolumn{4}{|c|}{ Number of Children Ever Born } \\
\hline $1-4$ & 1 & & \\
\hline $5-16$ & $\begin{array}{l}3.24(3.09- \\
3.40)^{* * *}\end{array}$ & & \\
\hline \multicolumn{4}{|l|}{ Children Died } \\
\hline No & 1 & & \\
\hline Yes & ${ }_{* * *} .19(1 . .9-1.31)$ & & \\
\hline \multicolumn{4}{|l|}{ Daughters Died } \\
\hline No & & 1 & 1 \\
\hline Yes (1 to 5) & & $\begin{array}{l}1.24(1.11- \\
1.37)^{* * * *}\end{array}$ & $1.55(1.49-1.62)^{* * * *}$ \\
\hline \multicolumn{4}{|l|}{ Sons Died } \\
\hline No & 1 & 1 & 1 \\
\hline Yes & $1.12(1.04-1.24)$ & $1.56(1.40-1.74)$ & $1.55(1.48-1.616)^{* * * 4}$ \\
\hline \multicolumn{4}{|l|}{ Miscarriages } \\
\hline No & & & 1 \\
\hline Yes & & & $1.30(1.26-1.35)^{* * * *}$ \\
\hline \multicolumn{4}{|c|}{ History of Abortions } \\
\hline No & 1 & 1 & 1 \\
\hline Yes & $\begin{array}{l}1.31(1.21- \\
1.43)^{* * * *}\end{array}$ & $1.53(1.41-1.66)$ & $1.25(1.20-1.29)^{* * * *}$ \\
\hline \multicolumn{4}{|c|}{ C Section Delivery } \\
\hline No & 1 & 1 & 1 \\
\hline Yes & $.26(.23-.31)^{* * * *}$ & $.73(.65-82)^{* * *}$ & $.25(.21-.30)^{* * *}$ \\
\hline
\end{tabular}

1 the table shows results of binary logistic regression analysis. insignificant results are not stated in the table

abbreviations: $\mathrm{OR}=$ odds ratio, $\mathrm{CI}=$ confidence interval, $1=$ reference category

\section{Discussion}

The results confirmed the association of social demographics (Bhatti \& Jeffery, 2012), child mortality (Mekonnen \& Worku, 2011) and reproductive profile (Olusanya \& Solanke, 2009) with number of living children, ideal number of children and desire to 
reproduce more (Bhat \& Zavier, 2003). The desire to reproduce more children among young women has reduced over time from 2007 to 2013 with odds of 19 to .09. Likewise, rural place of residence is associated with less likelihood of high number of ideal children in 2013 as compared to previous association of rural residence and five plus ideal children in 2007.Hence, women's place of residence, illiteracy, unemployment and poverty are significantly associated with fertility and fertility preferences (Pande \& Astone, 2007).

Another positive trend assessed through comparative analysis is that the desire to reproduce more children also decreased among women with one or several C-section deliveries. Furthermore, women with history of abortions are more likely to have five plus ideal number of children in 2013. On the contrary, this association is found to be an inverse previously in 2007. Prospective researches are needed to find out socio-economic reasons behind this increased likelihood of high number of idealized children among women with history of abortions.

Delivery complications such as: injection induced labour pains, C-section deliveries, fistula problem and spotting during gestation are associated significantly with lower ideal number of children. Complicated pregnancies and deliveries restrict women's reproductive career significantly. In contrast the women who reported severe headache and epigastric pains during gestation are more likely to have higher ideal number of children. This can be attributed to the social behaviour of women that regards headache and epigastric pains as normal in pregnant women. History of abortions, caesarian section, fistula problem, vaginal bleeding and injection induced labour pains are found to be associated with desire to reproduce more, few ideal and living children (Bose \& Trent, 2006). In the cases of stillbirths, mothers have higher desire to reproduce more. But perhaps the medical complications limit the number of births in such cases. Complain of blurring vision in pregnancies is associated with no desire to reproduce more.

Moreover, the illiterate and poor women have higher number of living children. The male and female child mortality is associated with reproducing many living children (Zhang, 1990). In contrast; the history of abortions, C-section deliveries, injection induced labour pains are associated with few living children. Women suffering from severe headache, blurring of vision and epigastric pains have higher number of living children. Again, this can be attributed to the common acceptance of health problems during gestation in Pakistani society (Toor, 2007; Adhikari, 2010).

In short, our findings highlight the importance of empowering women of rural areas through secondary and higher education, employment, good wages and reproductive health facilities (Hayford \& Agadjanian, 2012). At community level, the concern for improved lifestyle may reduce fertility rate further in Pakistan. The deaths of several sons 
and daughters reveal similar trends as if the mothers keep on reproducing until few or several live births, irrespective of child's gender (McAllister et al., 2012;Jain \& Ross, 2012). Nationally representative data collected by Pakistan Demographic and Health Survey is the major strength of this study. However, the unavailability of same variables in compared data sets prevented assessment on several occasions. This study is subject to certain limitations associated with the cross sectional survey design, use of variables in PDHS and missing information. Moreover, the causal relationship is not assessed in this paper. Also, the mutual association of dependent variables is not analyzed. The binary measures also provide a rough estimate of the association between variables. However, it provides a useful insight into the determinants of fertility and fertility preferences of women in Pakistan by using PDHS 2006-07 and 2012-13.

\section{Conclusions}

Findings support the association of socio-demographic and health determinants with ideal number of children, living children and desire to reproduce more. The societal development and improvement in the lifestyle of masses may further reduce fertility rate. Efforts should be directed to improve reproductive health services in Pakistan. The desire to reproduce more in association with women's age 15-29, rural place of residence and C-section deliveries has reduced over time from 2007 to 2013 in country. Improving women empowerment situation may help making fertility and reproductive preferences prodevelopment of Pakistan. Future researches should adopt a sequential mixed methodology design to study factors of fertility and fertility preferences in order to address the weaknesses of both quantitative and qualitative methodologies. Policies should focus on improving women education, reproductive health facilities, and family planning service provision to have national level effects on fertility and fertility preferences.

\section{Acknowledgements}

The authors gratefully acknowledge MEASURE DHS for providing access to the data of Pakistan Demographic and health Survey (2006-07).

\section{References}

Adhikari, R. (2010). Demographic, Socio-Economic, and Cultural Factors Affecting Fertility Differentials in Nepal. BioMed Central Pregnancy and Childbirth, vol.10, p.19.

Ali, S. M. (1989). Determinants of Family Size Preference in Pakistan. The Pakistan Development review, vol.28:3, pp.207-231. 
Arnold, F., Choe, M. K. \& Roy, T. K. (1998). Son Preference, The Family-Building Process and Child Mortality in India. Population Studies, vol.52:3, pp.301-315.

Basu, D. \& De Jong, R. (2010). Son Targeting Fertility Behaviour: Some Consequences and Determinants. Demography, vol.47:2, pp.521-536.

Bhat, P. N. \& Zavier, A. J. (2003). Fertility Decline and Gender Bias in Northern India. Demography, vol.40:4, pp.637-657.

Bhatti, F. \& Jeffery, R. (2012). Girl's Schooling and Transition to Marriage and Motherhood: Exploring the Pathways to Young Women's Reproductive Agency in Pakistan. Comparative education, vol.48:2, pp.149-166.

Bose, S. \& Trent, K. (2006). Socio-Demographic Determinants of Abortion in India: A North-South Comparison. Journal of Biosocial Science, vol.38:2, pp.261-282.

Brunson, J. (2010). Son Preference in the Context of Fertility Decline: Limits to New Constructions of Gender and Kinship in Nepal. Studies in family planning, vol.41:2, pp.89-98.

Chauhduri, S. (2012). The Desire for Sons and Excess Fertility: A Household-Level Analysis of Parity Progression in India. International Perspectives on Sexual and Reproductive Health, vol.38:4, pp.178-186.

Debpuur, C., Depbuur, C. \& Bawah, A. G. (2002). Are Reproductive Preferences Stable? Evidence from Rural Northern Ghana. Genus, vol.58:2, pp.63-89.

Doblhammer, G. (2000). Reproductive History and Mortality Later in Life: A Comparative Study of England and Wales and Austria. Population Studies, vol.54, pp.169-176.

Freedman, R. (1997). Do Family Planning Programs Affect Fertility Preferences? A Literature Review. Studies in Family Planning, vol.28:1, pp.1-13.

Gilks, W. R. (1986). The Relationship between Birth History and Current Fertility in Developing Countries. Population Studies, vol.40, pp.437-455.

Harrison, A. \& Montgomery, E. (2001). Life Histories, Reproductive Histories: African Women's Narratives of Fertility, Reproductive Health and Illness. Journal of Southern African Studies, vol.27:2. 
Hayford, S. R. \& Agadjanian, V. (2012). From Desires to Behaviour: Moderating Factors in a Fertility Transition. Demographic Research, vol.26, pp.511-542.

Hussain, R., Fikree, F. F. \& Berendes, H. W. (2000). The Role of Son Preference in Reproductive Behaviour in Pakistan. Bulletin of the World Health Organization, vol.78:3, pp.379-388.

Jain, A. K. \& Ross, J. A. (2012). Fertility Differences Among Developing Countries: Are They Still Related to Family Planning Program Efforts and Social Settings? International Perspectives on Sexual and Reproductive Health, vol.38:1, pp.15-22.

Javachandran, S. \& Kuziemko, I. (2011). Why Do Mothers Breastfeed Girls Less than Boys? Evidence and Implications for Child Health in India. The Quarterly Journal of Economics, vol.126:3, pp.1485-1538.

Jayaraman, A., Mishra, V. \& Arnold, F. (2009). The Relationship of Family Size and Composition To Fertility Desires, Contraceptive Adoption and Method Choice in South Asia. International Perspectives on Sexual and Reproductive Health, vol.35:1, pp.29-38.

Larsen, U., Chung, W. \& Das Gupta, M. (1998). Fertility and Son Preference in Korea. Population Studies, vol.52:3, pp.317-325.

Ma, K. Z. M., Norton, E. C. \& Lee, S. D. (2010). Declining Fertility and the Use of Cesarean Delivery: Evidence from a Population-Based Study in Taiwan. Health Services Research, vol.45, pp.1360-1375.

McAllister, L., Gurven, M., Kaplan, H. \& Stieglitz, J. (2012). Why Do Women have More Children than They Want? Understanding Differences in Women's Ideal and Actual Family Size in a Natural Fertility Population. American Journal of Human Biology, vol.24:6, pp.786-799.

Mekonnen, W. \& Worku, A. (2011). Determinants of Fertility in Rural Ethiopia: The Case of Butajira Demographic Surveillance System (DSS). BioMedCental Public Health, 11: 782 .

Olusanya, B. O. \& Solanke, O. A. (2009). Maternal and Neonatal Factors Associated with Mode of Delivery Under a Universal Newborn Hearing Screening Programme in Lagos, Nigeria. BMC Pregnancy and Child Birth, DOI: 10.1186/ 1471-2393-9-41 
Pande, R. P. \& Astone, N. M. (2007). Explaining Son Preference in Rural India: The Independent Role of Structural Versus Individual Factors. Population Research Policy Review, vol.26, pp.1-29.

PDHS (2006-07). Pakistan Demographic and Health Survey. National Institute of Population Studies (NIPS), Islamabad, Pakistan and Macro International.

PDHS (2012-2013). Pakistan Demographic and Health Survey. Preliminary Report, National Institute of Population Studies, Islamabad, Pakistan and MEASURE DHS, ICF International, Calverton, Maryland, USA.

Roy, T. K., Sinha, R. K., Koenig, M., Mohanty, S. K. \& Patel, S. K. (2008). Consistency and Predictive Ability of Fertility Preference Indicators: Longitudinal Evidence from Rural India. International Family Planning Perspectives, vol.34:3, pp.138145.

Sathar, Z. A. \& Casterline, J. B. (1998). The Onset of Fertility Transition in Pakistan. Population and Development Review, vol.24:4, pp.773-796.

Sheikh, L., Najmi, N., Khalid, U. \& Saleem, T. (2011). Evaluation of Compliance and Outcomes of a Management Protocol for Massive Postpartum Hemorrhage at a Tertiary Care Hospital in Pakistan. BMC Pregnancy and Childbirth, vol.11, p.28.

Toor, I. A., (2007). Return to Education, The Case of Fertility. Pakistan Economic and Social Review, vol.45:1, pp.107-123.

UNDESA (2011).United Nations Department of Economic and Social Affairs. World Population Prospects: 2010 Revision.

Vlassoff, M., Singh, S., Saurez, G., et. al. (2009). Abortions in Pakistan. In Brief, New York: Guttmacher Institute 2009, No. 2. www.guttmacher.org/pubs/ IB_Abortionin-Pakistan.pdf

Zhang, J. (1990). Socio-Economic Determinants of Fertility in China: A Micro Econometric Analysis. Journal of Population Economics, vol.3:2, pp.105-123. 
Aisha Jalil is Doctoral Candidate in Sociology, Institute of Social and Cultural Studies, University of the Punjab.

Rubeena Zakar is an Associate Professor in Public Health, Institute of Social and Cultural Studies, University of the Punjab.

Ahmed Usman is an Assistant Professor in Sociology, Institute of Social and Cultural Studies, University of the Punjab.

Aaisha Amjad is M.Phil Student in Sociology, Institute of Social and Cultural Studies, University of the Punjab. 